\title{
Sejamos abertos, sempre!
}

\section{Let's be open forever! ¡Seamos abiertos, siempre!}

Josué Laguardia |josue.laguardia@icict.fiocruz.br

Fundação Oswaldo Cruz, Instituto de Comunicação e Informação Científica e Tecnológica em Saúde, Laboratório de Informação em Saúde, Proqualis. Rio de Janeiro, Brasil.

Palavras-chave: saúde coletiva; comunicação; Reciis; acesso aberto; periódicos científicos.

Keywords: collective health; communication; Reciis; open access; scientific journals.

Palabras clave: salud colectiva; comunicación; Reciis; acceso abierto; revistas periódicas.

O papel destacado que os trabalhos científicos relacionados à informação em saúde tiveram ao longo das décadas de 1980 e 1990, nas revistas que tratam da saúde coletiva, foi sendo progressivamente ocupado por artigos vinculados aos estudos epidemiológicos, seja na divulgação dos resultados de pesquisa ou no debate acerca de questões metodológicas.

A criação da Revista Eletrônica de Comunicação, Informação \& Inovação em Saúde - Reciis, em 2007, possibilitou aos pesquisadores interessados nas questões relacionadas à informação, em suas diferentes conexões com a saúde, o acesso a uma publicação cujo escopo está centrado nos temas relacionados a esse campo e à sua interface com a comunicação. Ao longo dos últimos 10 anos, a revista tem desempenhado um papel importante na constituição de um espaço de interlocução e de divulgação dos trabalhos realizados em duas áreas importantes: comunicação e saúde, por um lado; informação e/em/para saúde, por outro.

A introdução de números temáticos a partir do segundo ano de sua existência trouxe um aprofundamento de discussões relevantes à área da saúde, ao abordar a ética em pesquisa, saúde global e educação permanente, e às questões relacionadas às políticas, aos processos e às perspectivas comunicacionais e de acesso aberto, bem como às ontologias e tecnologias de informação.

Entre os desafios colocados à Reciis, a adoção de uso da plataforma Open Journal Systems (OJS), um sistema de código livre gratuito para a administração e a publicação de revistas, estava em total concordância com a política em curso na instituição e da qual o Instituto de Comunicação e Informação Científica e Tecnológica em Saúde - Icict - foi o principal fomentador. A Reciis foi o primeiro periódico da Fundação Oswaldo Cruz - Fiocruz - a adotar essa ferramenta e a sua experiência serviu de modelo e incentivo para a criação de outros periódicos institucionais, colocando em discussão o uso de plataformas proprietárias. 
Outro desafio enfrentado pelos editores foi a opção de publicar cada número da revista em dois idiomas - português e inglês, a despeito das atribulações relacionadas tanto ao custo financeiro quanto à expertise técnica de tradutores que dessem conta dos diversos temas nas várias especialidades do conhecimento. Um terceiro desafio, que se coloca como o mais importante neste momento, é a garantia da sua manutenção como revista institucional de acesso aberto, face à hegemonia dos periódicos 'internacionais' pertencentes a grandes grupos editoriais.

O modelo de qualificação das revistas científicas, tal como estabelecido pelo sistema Qualis/ Capes, associado às ações pontuais de financiamento de revistas institucionais nacionais e à política de internacionalização das publicações da produção científica brasileira, pode representar uma sentença de morte às publicações que, como a Reciis, lutam para garantir que autores e leitores não paguem pelo acesso às informações científicas derivadas de estudos financiados com recursos públicos. Antes de embarcar em determinadas canoas por mares desconhecidos, com risco de ir a pique, talvez seja melhor seguirmos a sugestão de Fortes1, em 2016, "de investir tempo e recursos no aprimoramento e profissionalização das publicações brasileiras e na tradução e publicação, no país, de trabalhos relevantes em outros idiomas", evitando um "cosmopolitismo científico de cócoras".

\section{Referências}

1. Fortes R. Política científica no Brasil: dilemas em torno da internacionalização e do inglês. Interfaces. 2016;6(1):151-190. 